\title{
Reimplantation of an anomalous left innominate artery with Kommerell diverticulum arising from a right aortic arch
}

\author{
David N. Ranney, MD, Nicholas D. Andersen, MD, and Robert D. B. Jaquiss, MD, Durham, NC
}

\author{
From the Division of Pediatric Cardiothoracic Surgery, Duke University Medical Center, Durham, NC. \\ Disclosures: Authors have nothing to disclose with regard to commercial support. \\ Received for publication Sept 9, 2015; accepted for publication Oct 8, 2015; available ahead of print Nov 6, 2015. \\ Address for reprints: Robert D. B. Jaquiss, MD, Division of Pediatric Cardiothoracic Surgery, Duke University \\ Medical Center, Box 3051, Durham, NC 27710 (E-mail: robert.jaquiss@dm.duke.edu). \\ J Thorac Cardiovasc Surg 2016;151:e37-9 \\ $0022-5223 / \$ 36.00$ \\ Copyright (C 2016 by The American Association for Thoracic Surgery \\ http://dx.doi.org/10.1016/j.jtcvs.2015.10.031
}

A 14-month-old boy with symptomatic tracheal compression was found to have a right aortic arch with an anomalous left innominate artery arising from a diverticulum of Kommerell. This malformation was managed by dividing the ligamentum arteriosum and reimplanting the innominate artery onto the ascending aorta in an effort to relieve compression of this uncommon complete vascular ring.

\section{CLINICAL SUMMARY}

The patient is a 14-month-old boy who presented with stridor, recurrent respiratory infections, and tracheobronchomalacia that had been managed with tracheostomy. His previous medical history was significant for thoracic wall dystrophy, hydrocephalus requiring ventriculoperitoneal shunt, adrenal insufficiency, solitary kidney, and partial DiGeorge syndrome with hypoparathyroidism. Several transthoracic echocardiograms documented a right aortic arch. Because of repetitive episodes of apparent airway obstruction after tracheostomy, computed tomographic angiography was performed and demonstrated a right aortic arch with aberrant left innominate artery arising from a diverticulum of Kommerell coursing posterior to the trachea and bifurcating into left subclavian and left carotid arteries (Figure 1). A ligamentum arteriosum was suspected to complete the vascular ring, leading to focal narrowing of the distal trachea to $4 \mathrm{~mm}$, versus a diameter of $10 \mathrm{~mm}$ at the thoracic inlet.

After treatment for polymicrobial respiratory infection, the patient's condition was considered medically optimized for operative intervention. The patient was orally intubated, and the previous tracheostomy tube was removed. Median sternotomy was performed. The pericardium was opened vertically, and the anticipated anatomy was encountered. The aorta was mobilized distal to the takeoff of the anomalous left innominate artery. The ligamentum arteriosum was identified (Figure 2, $A$ ), suture ligated, and divided. Attention was then turned to the diverticulum of Kommerell. Because of the potential for aneurysmal dilatation with progressive tracheal compression, the decision was made to

\section{DISCUSSION}

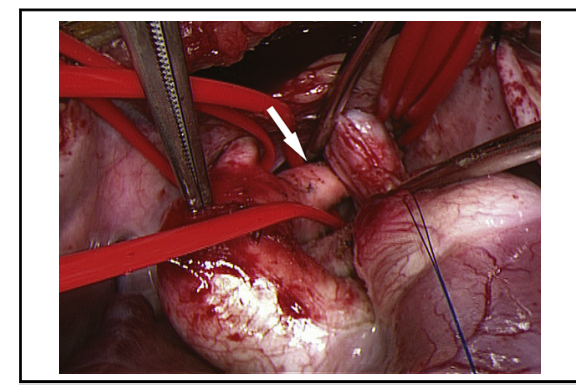

Right aortic arch with an aberrant left innominate artery (arrow)

Central Message

A rare vascular ring caused by an anomalous left innominate artery from a right aortic arch was managed by division and reimplantation.

See Editorial Commentary page e39.

transpose the anomalous innominate artery. The left carotid and left subclavian arteries were controlled distally with vessel loops (Figure 2, B), and the innominate artery was clamped and divided at its base. The aortic end was oversewn, eliminating the diverticulum, and the innominate artery was reimplanted on the distal ascending aorta, anterior to the trachea (Figure 2, $C$ and $D$ ). The patient tolerated surgery without postoperative complications. The tracheostomy tube was reinserted, and he was discharged to be weaned from the ventilator at home.

Vascular rings are anatomic aberrancies that can result in symptomatic compression of the trachea or esophagus. They are frequently associated with other congenital cardiovascular lesions. Normally, left and right dorsal aortic arches coexist until the third week of development, after which the right-sided arch regresses. If the left fourth arch regresses proximal to the left common carotid artery with persistence of the left dorsal aortic root and ductus arteriosus, it results in a malformation described as a right aortic arch with aberrant left innominate artery. ${ }^{1}$ In this particular morphology, a complete vascular ring is formed by the aortic arch on the right, pulmonary artery anteriorly, anomalous left innominate artery posteriorly, and ligamentum arteriosum on the left. A variation of this anatomy occurs when the aberrant artery arises from a remnant of the left fourth arch, termed the diverticulum of Kommerell. 


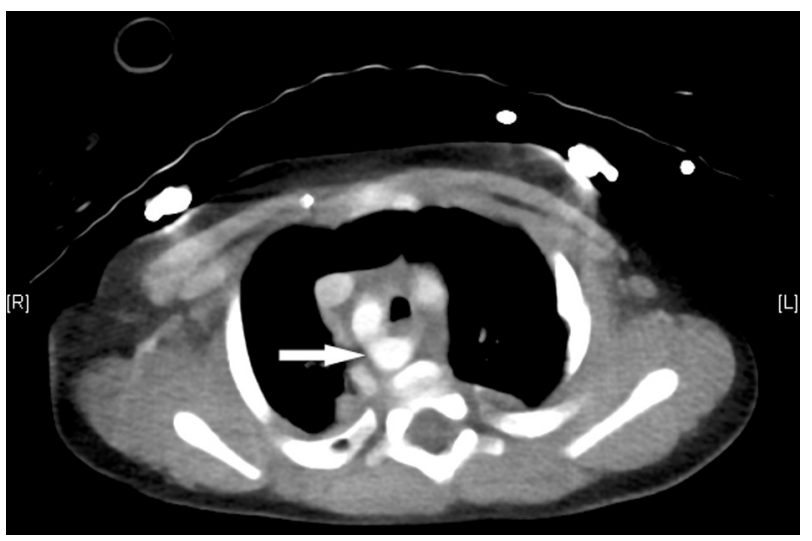

FIGURE 1. Preoperative computed tomographic angiography demonstrating a right aortic arch with the origin of an aberrant left innominate artery (arrow) arising from a diverticulum of Kommerell and coursing posterior to the trachea. The distal trachea was narrowed to $4 \mathrm{~mm}$ in the area of the vascular ring.

Aneurysmal dilatation of this diverticulum can contribute additional compressive forces to the trachea and esophagus. ${ }^{1}$

Symptoms of a vascular ring include stridor, dyspnea, recurrent respiratory infections, and dysphagia. Evidence of their existence can be observed on chest radiography, barium esophagography, and echocardiography; however, computed tomographic angiography with 3-dimensional reconstruction remains the best modality for preoperative planning, and magnetic resonance angiography can be used as an alternative. ${ }^{2}$ Bronchoscopy can be used to detect coexisting pathology that may also be contributing to symptoms (eg, tracheomalacia). Operative intervention is indicated for the patient with symptoms and evidence of compression on radiographic imaging or bronchoscopy. Asymptomatic cases have been reported in which the affected patients did not undergo operative intervention. ${ }^{1}$

This particular anatomy is quite rare, and only 12 cases have previously been reported in the literature to our knowledge. ${ }^{1}$ Surgical approaches to repair include median sternotomy, thoracotomy, and video-assisted thoracic surgery. ${ }^{1}$ Division of the ligamentum arteriosum is the accepted technique for tracheoesophageal decompression. Resection of the diverticulum of Kommerell with vessel reimplantation is not always performed, in part because of technical feasibility. It has been suggested that resection and vessel reimplantation should be performed whenever possible, however, because late complications of Kommerell diverticulum, including persistent symptoms caused by
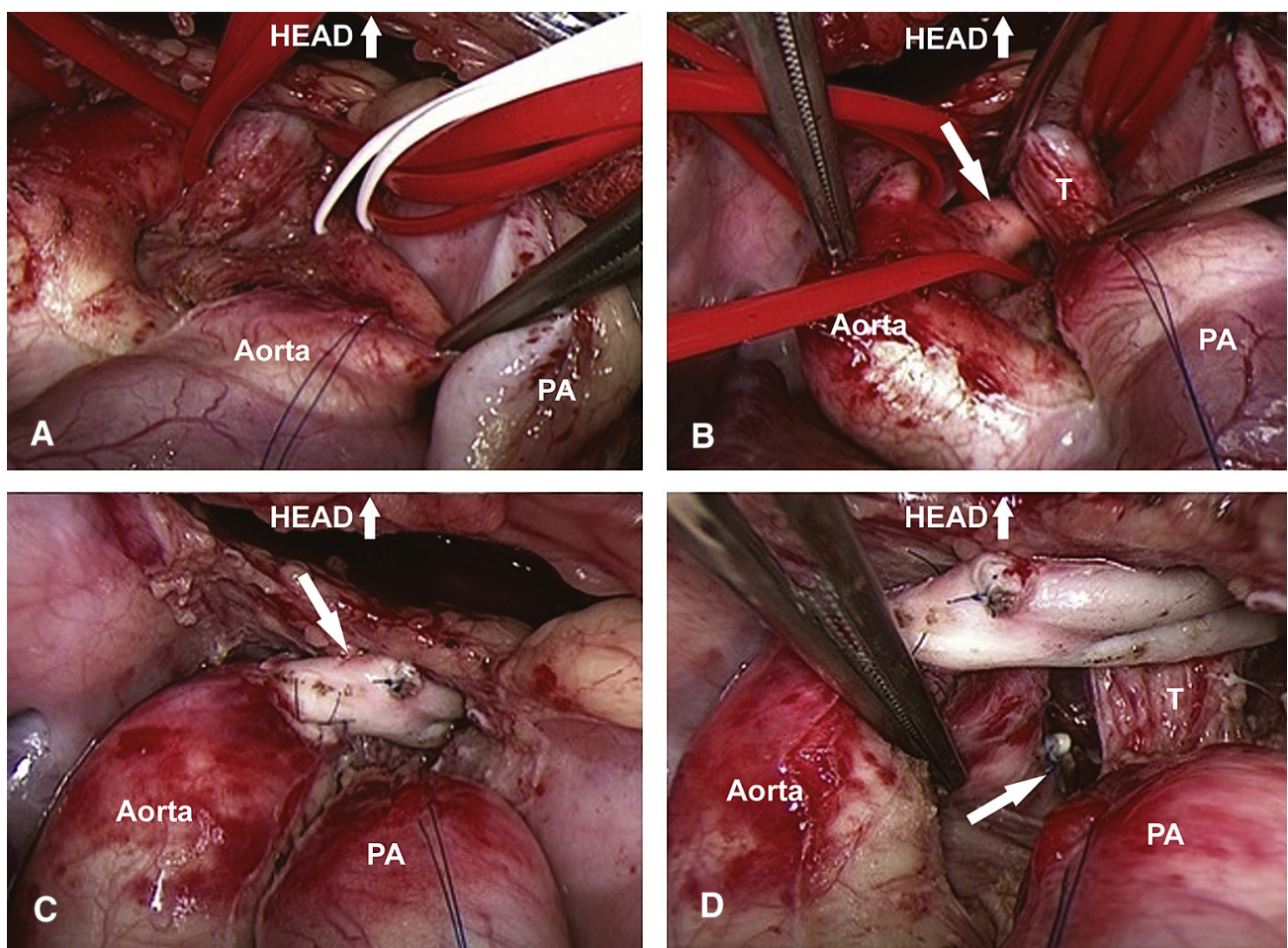

FIGURE 2. Reimplantation of the aberrant left innominate artery to the ascending aorta. A and B, Large vessel loops surround the origin of the aberrant artery and its 2 distal branches on either side of the trachea. A, White vessel loop encircling the ligamentum arteriosum. B, Aberrant left innominate artery arising from a diverticulum of Kommerell posterior to the trachea (arrow). C, Reimplanted left innominate artery onto the ascending right aortic arch (arrow). D, Retraction of the aorta to reveal the original location of the left innominate artery and the ligated aortic stump of the Kommerell diverticulum (arrow). PA, Pulmonary artery; $T$, trachea. 
compression by the diverticulum or even late aneurysmal dilatation of the diverticulum with rupture or dissection, are known to occur. ${ }^{3-5}$

\section{References}

1. Banka P, Geva T, Powell AJ, Geggel R, Lahiri T, Valente AM. Images in cardiovascular medicine. Right aortic arch with aberrant left innominate artery: a rare vascular ring. Circulation. 2009;120:264-5.
2. Calcagni G, Gesualdo F, Brunelle F, Ou P. An unusual case of left aberrant innominate artery with right aortic arch: evaluation with high-resolution CT. Pediatr Radiol. 2008;38:115-7.

3. Backer CL, Russell HM, Wurlitzer KC, Rastatter JC, Rigsby CK. Primary resection of Kommerell diverticulum and left subclavian artery transfer. Ann Thorac Surg. 2012;94:1612-7.

4. Cinà CS, Althani H, Pasenau J, Abouzahr L. Kommerell's diverticulum and right-sided aortic arch: a cohort study and review of the literature. J Vasc Surg. 2004;39:131-9.

5. Shinkawa T, Greenberg SB, Jaquiss RD, Imamura M. Primary translocation of aberrant left subclavian artery for children with symptomatic vascular ring. Ann Thorac Surg. 2012;93:1262-5.

\title{
EDITORIAL COMMENTARY
}

\section{Rare but relevant}

\author{
E. Dean McKenzie, MD
}

\footnotetext{
From the Division of Congenital Heart Surgery, Texas Children's Hospital, and the Michael E. DeBakey Department of Surgery, Baylor College of Medicine, Houston, Tex.

Disclosures: Author has nothing to disclose with regard to commercial support.

Received for publication Oct 22, 2015; accepted for publication Oct 22, 2015; available ahead of print Nov 21, 2015.

Address for reprints: E. Dean McKenzie, MD, Congenital Heart Surgery, Texas Children's Hospital, 6621 Fannin St MC19345H, Houston, TX 77030 (E-mail: edmckenz@texaschildrens.org).

J Thorac Cardiovasc Surg 2016;151:e39-40 $0022-5223 / \$ 36.00$

Copyright (C 2016 by The American Association for Thoracic Surgery

http://dx.doi.org/10.1016/j.jtcvs.2015.10.084
}

Even though the anomaly discussed in this issue of the Journal is rare, vascular rings are common problems for congenital heart surgeons. Right aortic arch (RAA) with aberrant left innominate artery, though extremely rare, is very similar anatomically and pathophysiologically to the more common RAA with aberrant left subclavian artery (ALSCA) and posterior ligamentum. We should therefore make note of Drs Ranney, Andersen, and Jaquiss' successful surgical management.

A Kommerell diverticulum (KD) represents persistent dilation or enlargement of the base of the subclavian artery, or in this case innominate artery, after having accommodated half of the cardiac output during fetal life. Although the KD may become aneurysmal later in life, it need not be aneurysmal to cause problems. Because of its location between the spine and the esophagus, it may be a cause of dysphagia and other swallowing difficulties before or after division of the ligamentum.

For patients with a vascular ring secondary to RAA, ALSCA, KD, and posterior ligamentum who have swallowing difficulties, one should strongly consider complete removal of the KD from the descending aorta with translocation of the ALSCA to the left common carotid artery (Figure 1). For an excellent discussion of the technique,

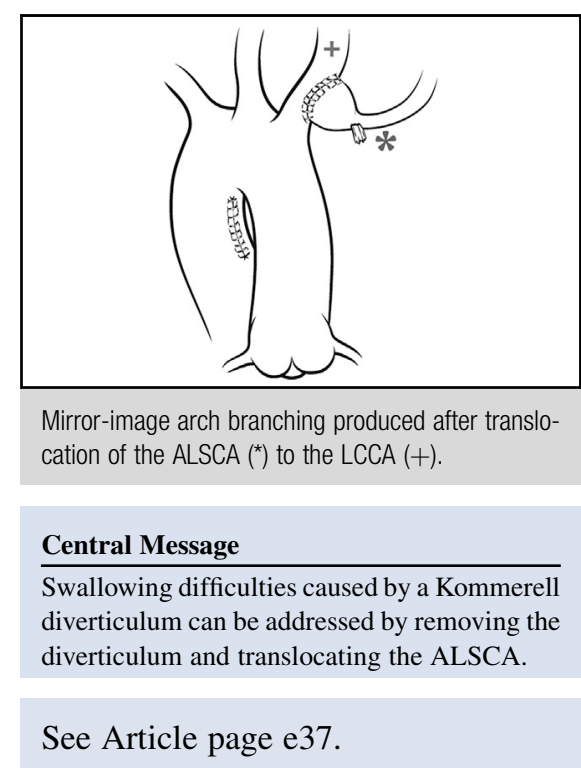

one may refer to the article of Backer and colleagues ${ }^{1}$ referenced in the bibliography.

To translocate the aberrant left innominate artery, the authors wisely chose an anterior approach through a sternotomy for optimal exposure of the distal ascending aorta. This rare anomaly represents one of the few situations in which left thoracotomy or thoracoscopy is not the best approach for treatment of a vascular ring. A limited left posterolateral 3rd interspace thoracotomy provides excellent exposure. Anticoagulation with heparin and monitoring of left cerebral near infrared spectroscopy, technical details not mentioned in the article, are useful for increased safety. Transection of the diverticulum flush 